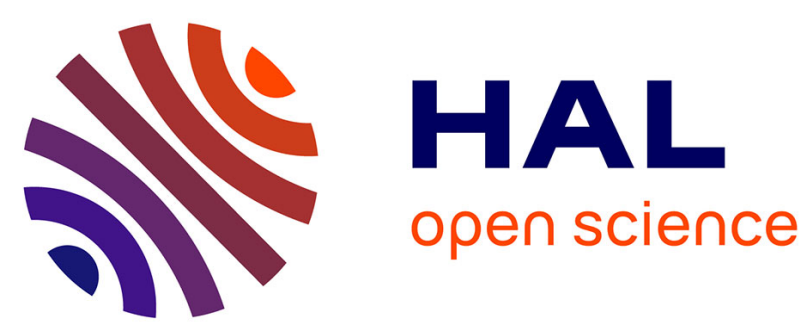

\title{
Insulin Pump Failures: Has There Been an Improvement? Update of a Prospective Observational Study
}

Agathe Guenego, Guillaume Bouzillé, Stéphanie Breitel, Annabelle Esvant, Jean-Yves Poirier, Fabrice Bonnet, Isabelle Guilhem

\section{To cite this version:}

Agathe Guenego, Guillaume Bouzillé, Stéphanie Breitel, Annabelle Esvant, Jean-Yves Poirier, et al.. Insulin Pump Failures: Has There Been an Improvement? Update of a Prospective Observational Study. Diabetes Technology and Therapeutics, 2016, 18 (12), pp.820-824. 10.1089/dia.2016.0265 . hal-01447070

\section{HAL Id: hal-01447070 https://hal-univ-rennes1.archives-ouvertes.fr/hal-01447070}

Submitted on 14 Mar 2017

HAL is a multi-disciplinary open access archive for the deposit and dissemination of scientific research documents, whether they are published or not. The documents may come from teaching and research institutions in France or abroad, or from public or private research centers.
L'archive ouverte pluridisciplinaire HAL, est destinée au dépôt et à la diffusion de documents scientifiques de niveau recherche, publiés ou non, émanant des établissements d'enseignement et de recherche français ou étrangers, des laboratoires publics ou privés. 
Insulin pump failures: has there been an improvement? Update of a prospective observational study

A.Guenego ${ }^{1,2}$, G. Bouzillé2, ${ }^{2,3}$ S. Breitel ${ }^{4}$, A. Esvant ${ }^{1,2}$, J-Y. Poirier ${ }^{1}$, F. Bonnet ${ }^{1,2}$, I. Guilhem $^{1}$

${ }^{1}$ CHU de Rennes, Department of Endocrinology, Diabetes and Nutrition, Hôpital sud, 16

boulevard de Bulgarie- F-35033, Rennes, France

${ }^{2}$ Université de Rennes 1, Rennes, F-35000, France

${ }^{3}$ INSERM, U1099, Rennes, F-35000, France

CHU Rennes, CIC Inserm 1414, Rennes, F-35000, France

${ }^{4}$ AIR de Bretagne, Z.A.C Atalante Villejean, 8 Rue Jean-Louis Bertrand, 35000 Rennes, France

Corresponding author: Isabelle Guilhem, Department of Endocrinology, Diabetes and Nutrition,

CHU de Rennes, Hôpital Sud, 16 Bd de Bulgarie, BP 90347, 35203 RENNES Cedex 2

Phone: +33299267118

Fax: +33299267149

E-mail: isabelle.guilhem@chu-rennes.fr

Running title: insulin pump failures

Keywords: Continuous subcutaneous insulin infusion, insulin pump, postmarket surveillance, insulin pump failures 


\section{Abstract}

Background: Insulin pump failures had been assessed in our center by a prospective observational study from 2001 to 2007 . The aim of this study was to update our data since 2008 and to determine if there exist specific risk factors for insulin pump failures.

Methods: All insulin pumps defects were prospectively collected between 2008 and 2013 in a monocentric cohort of 350 new pumps. Clinical consequences were recorded. Brand and model of pumps, type of defects and patients' characteristics (gender, age at diabetes diagnosis, age at first pump, pump treatment duration, number of previous pumps and number of previous pump failures) were tested for possible association with insulin pump failure.

Results: Malfunctions occurred in $239(68 \%)$ pumps. The incidence rate was 33/100 pumpyears. There were $28(12 \%)$ complete failures, $17(7 \%)$ alarms, $83(35 \%)$ mechanical defects and 105 (44\%) minor defects. Survival curves did not differ according to pump brand and model. Hyperglycaemia occurred in $2.9 \%$ of cases. In multivariate analysis, only patient age under 40 at the initiation of pump therapy was associated with higher risk of malfunction (HR $1.64 ; 95 \% \mathrm{Cl} 1.19-2.24 ; \mathrm{p}=0.002)$.

Conclusions: Pump malfunctions remain common with modern pumps. We report less complete failures than in our previous study. This could be due to improvement in pumps or to our strategy of systematic screening and replacement in case of mechanical defects.

Abbreviations: $\mathrm{CSII}=$ Continuous subcutaneous insulin infusion; $\mathrm{AIRB}=$ Air de Bretagne 


\section{Background}

Continuous subcutaneous insulin infusion (CSII) therapy has been used for nearly 40 years ${ }^{1}$ and is an efficient and flexible treatment to improve both glycaemic control and quality of life ${ }^{2-4}$. However, insulin pump dysfunctions may have severe consequences ${ }^{5,6}$. In spite of this, the clinical studies required by regulators prior to marketing new insulin pumps are limited and insufficient data is made publicly available on their long-term use in real-life setting ${ }^{7}$. We had determined the rate of insulin pump failure, excluding problems linked to infusion set defects, by a prospective observational study ${ }^{8}$. During this six-year study (2001-2007), 36\% of our pumps broke down after a median time of 15 months. The current study was undertaken to update our data. The aim was to reassess the rate and the clinical consequences of pump defects and to establish whether some patients' characteristics are associated with an increased risk of malfunctions.

\section{Methods}

We prospectively studied the defects occurring between June 2008 and December 2013 on new insulin pumps used in ambulatory CSII. We included all pumps acquired between June 2008 and December 2011 by our partner, AIR de Bretagne (AIRB), a not-for-profit association in charge of the maintenance and supply of pumps.

Each CSII treatment had been initiated in an inpatient setting. Patients were given a choice between pumps manufactured by Medtronic (Paradigm ${ }^{\circledR}$ 512/712, Paradigm ${ }^{\circledR}$ 522/722, Paradigm $^{\circledast}$ Veo $^{T M}$ ), Animas ${ }^{\circledast}(20 / 20)$ and Roche (Accucheck ${ }^{\circledast}$ Combo). They followed a specific education program including management of pump malfunctions. They were instructed to check glycemia in case of pump failure and ketones when glucose level was higher than $250 \mathrm{mg} / \mathrm{dl}$. The proper functioning of each component of the pump was systematically checked by healthcare professionals during at least four visits per year, and by patients themselves. 
Pump users benefited from a $24 / 7$ on-call medical service provided by diabetologists and a 24/7 technical hotline provided by AIRB.

The study focused on malfunctions directly related to the pump itself (and not infusion set problems), reported by the patient or identified during visits. According to the regulation on pump therapy in France, patients could not contact the manufacturer directly. Defects were always managed by AIRB and confirmed by the pharmacists in charge of surveillance devices. They were classified as: 1) complete failures that made pumps immediately unusable (blockage, continuous alarms, fixed screens and piston defects), 2) alarms that required pump replacement as recommended by the manufacturer, 3) mechanical defects (tank or batterychamber crack, pad dysfunction), 4) minor defects (other pump cracks and display defects). Complete failures and alarms were considered as severe failures.

The occurrence of hyperglycaemia $>250 \mathrm{mg} / \mathrm{l}$, presence of ketones, severe hypoglycaemiat and need for hospitalization were prospectively recorded in case of severe failure.

We expressed quantitative variables as median and interquartile range. We compared continuous variables with the Student $t$ test or Wilcoxon rank-sum test and discrete variables with the Khi-square test or Fisher's exact test, as appropriate. Pump survival was estimated with the Kaplan-Meier method and compared with a log-rank test. The parameters tested for possible association with pump failure were brands and pump models, types of failure and patients' characteristics (gender, age at diabetes diagnosis, age at first pump, CSII treatment duration, number of previous pumps and number of previous pump failures). A multivariate Cox proportional hazards analysis was performed to determine the independent predictors of pump failure. Values of $p<0.05$ were considered significant. Analyses were performed using $R$ statistical software, version 3.2.2.

\section{Results}


During the inclusion phase, 350 new pumps were acquired: 241 (69\%) Medtronic pumps, 74 (21\%) Animas and 35 (10\%) Roche pumps. The pumps were used by 248 adult diabetic patients (162 women, 86 men; median age 47 years [36 - 60]; median age at diagnosis of diabetes 18 years [11 - 28]; median age at CSII initiation 33 years [25 - 47]). There were $213(86 \%)$ type 1, $15(6 \%)$ type 2 and 20 (8\%) secondary or undetermined etiology diabetes.

Malfunctions occurred in 239 (68\%) pumps. Median survival time was 26 [IQR: 16-39] months (Fig. 1a). The rate of malfunction was 33 per 100 pump-years. There were 45 (19\%) severe pump failures (28 complete breakdown and 17 alarms set off); 83 (35\%) mechanical malfunctions, 105 (44\%) minor defects, cause was missing in six events (Table 1). Complete failures occurred earlier than other defects (13.5 [5-17.7] months versus 20 [11-27] months for alarms set off, 19 [13-26] months for mechanical defects and 24 [16-29.2] months for minor defects) $(p=0.0056)$ (Fig. 1b). All the damaged pumps were sent back to manufacturers who did not contest the defect.

There was no significant difference in survival curves according to pump brand and model (Fig. 1c). However, Medtronic pumps were more liable to mechanical defects ( $<<0.001$ ), Paradigm ${ }^{\circledast} 522 / 722$ pumps to minor defects $(p<0.001)$ and Paradigm ${ }^{\circledast}$ Veo $^{\text {TM }}$ pumps to alarms $(p<0.001)$ (Table 1).

Throughout the study, 174 patients (70 \%) experienced a pump defect, on one (71\%), two (22\%) or more $(7 \%)$ occasions. Neither type and duration of diabetes, duration of CSII treatment, number of previous insulin pumps, nor number of previous pump failures were associated with higher risk of breakdown. Female patients ( $\mathrm{HR}=1.40,95 \% \mathrm{Cl}$ 1.06-1.86; $\mathrm{p}=0.017)$ and those aged under 40 at the initiation of CSII $(\mathrm{HR}=1.59,95 \% \mathrm{Cl} 1.23-2.05 ; \mathrm{p}=$ 0.0003) (Fig. 1d) were more likely to experience pump failure In multivariate analysis, only age under 40 at the initiation of CSII remained significant (HR 1.64; 95\% Cl 1.19-2.24; $p=0.002$ ) (Supplementary material table 2). 
Mean $\mathrm{HbA} 1 \mathrm{C}$ levels were similar in patients with or without pump defect $(7.9 \% \pm 1.13$ versus $7.9 \% \pm 1.37 ; p=0.7)$, and whatever the cause of malfunction $(7.7 \% \pm 1.0$ for complete failure versus $7.9 \% \pm 1.22$ in other defects; $p=0.53$ ).

Six episodes of hyperglycemia (13\%) occurred following a severe pump failure $(n=45)$, which represents 0.47 events per 100 patient-years. No case of ketosis, hypoglycaemia or hospitalization has been recorded in relation to severe pump failure.

\section{Conclusions}

Our prospective observational study on pumps used in ambulatory CSII treatment over 5 years has shown a defect rate of 33/100 pump-years. Malfunctions were severe in $19 \%$ of cases but have had clinical consequences in only $13 \%$ of cases.

To our knowledge, our previous study carried out between 2001 and 2007 and the current update are the only prospective studies of pump defects reported after systematic verification by healthcare professionals, which was not supported by to the manufacturers. In most countries patients contact directly the manufacturers in case of malfunction. According to the FDA reports 1996-2005, Cope reported 1,594 events related to insulin pumps ${ }^{6}$. Other published data were obtained using phone interviews or questionnaires filled in by patients at the time of the incident ${ }^{9}$ or subsequently ${ }^{10,11}$. Data were mostly collected over short periods. Defect rates reported were $27 / 405$ patients $/ 16$ weeks $^{9} 46 \%{ }^{10}$ and $48 \%$ of patients ${ }^{11}$. Comparison with our first study suggests a lower proportion of severe ( $19 \%$ versus $72 \%$ ). This may indicate an improvement of the pumps. However, we observed an increase of $32 \%$ in the pump replacement rate (33 versus $25 / 100$ pump-years), mainly due to a mechanical and minor defects increase. Mechanical and minor defects in fact represented $35 \%$ and $44 \%$ respectively in this study, versus $18 \%$ and $9 \%$ in our previous study. We stress the considerable fragility of 
the outer shell and the keyboard, being the cause of $35 \%$ of the defects observed, mainly cracks. As mentioned in instruction manuals, cracks in the reservoir or battery compartment may lead to short-circuits or leakage. Based on these results, we recommend assessing the functioning of these pump components at each visit and instructing patients to do this, particularly after a pump impact or in case of water contact.

Interestingly, major breakdowns appeared earlier than less serious defects. This result agrees with the findings of Pickup ${ }^{11}$ who attributed it to the inexperience of novice patients. Another hypothesis could be a manufacturing defect leading to breakdown during the first year of use. Among our patients, in multivariate analysis, the only predictive factor of pump malfunction was age under 40 at the initiation of CSII. In order to explain this result, it could be important to collect data on other characteristics such as environmental factors, or psychosocial issues differing between generations. These factors (compliance, education, sports-related activities...) have already been suspected of contributing to adverse events in adolescent diabetic patients ${ }^{6,9}$. This needs to be confirmed in adults before personalization of education programs according to the patient's age.

Complications related to severe failures, were less frequent than in 2007 and seem to be less serious than those appearing in other studies ${ }^{6,9,12}$, probably because problems linked to the infusion set have not been included. In contrast with our results, Scaramuzza reported higher levels of HbA1c in breakdown cases ${ }^{10}$. As suggested by the authors, a potential loss of confidence in the technology may happen in breakdown cases and might have an impact on glycaemic control ${ }^{9}$.

The present study has intrinsic limitations. This "real-life" study does not allow a randomization by pump brand with an imbalance distribution in each brand. The statistical power was reduced by the late inclusion of some pumps resulting in a shorter duration of follow-up. A multicenter evaluation covering a larger population of pumps and patients would be useful. 
In conclusion, defects in insulin pumps remain a common issue in clinical practice. These findings suggest the importance of systematic screening in order to promote the prevention of serious breakdowns and their clinical repercussions. The reliability of pumps is even more crucial as they are to be used as part of an artificial pancreas.

\section{Legends:}

Table 1: Number of pump defects $(\mathrm{n})$ and time before defect $(\mathrm{t})$ according to pump model and type of defect. P-values were calculated for each type of defect comparing pump models.

Figure 1: Pumps survival curves. 1a-Overall survival time, with a median of 26 months. $1 \mathrm{~b}$ Survival according to failure type, $n=239$, log-rank $p$-value $=0.0056$. $1 c$ - Survival according to pump models, $n=350$, log-rank $p$-value $=0.058 .1 d-$ Survival according to age at pump initiation, $n=350$, log-rank $p$-value $<0.0001$. All survival analyses were censored the time of the pump defect or day of the last observation on December 31, 2013.

Author disclosure statement: the authors declare that there is no conflict of interest associated with this manuscript.

\section{References}

1. Pickup JC, Keen $\mathrm{H}$, Parsons JA, et al.: Continuous subcutaneous insulin infusion: an approach to achieving normoglycaemia. Br Med J. 1978;1(6107):204-207.

2. Misso ML, Egberts KJ, Page $M$, et al.: Continuous subcutaneous insulin infusion (CSII) versus multiple insulin injections for type 1 diabetes mellitus. Cochrane Database Syst Rev. 2010;(1):CD005103.

3. Pozzilli $P$, Battelino $T$, Danne $T$, et al.: Continuous subcutaneous insulin infusion in diabetes: patient populations, safety, efficacy, and pharmacoeconomics. Diabetes Metab Res Rev. 2016;32(1):21-39.

4. Giani E, Scaramuzza AE, Zuccotti GV: Impact of new technologies on diabetes care. World J Diabetes. 2015;6(8):999-1004.

5. Guilhem I, Leguerrier AM, Lecordier F, et al.: Technical risks with subcutaneous insulin infusion. Diabetes Metab. 2006;32(3):279-284. 
6. Cope JU, Morrison AE, Samuels-Reid J: Adolescent use of insulin and patient-controlled analgesia pump technology: a 10-year Food and Drug Administration retrospective study of adverse events. Pediatrics. 2008;121(5):e1133-1138.

7. Heinemann L, Fleming GA, Petrie JR, et al.: Insulin pump risks and benefits: a clinical appraisal of pump safety standards, adverse event reporting and research needs. A joint statement of the European Association for the Study of Diabetes and the American Diabetes Association Diabetes Technology Working Group. Diabetologia. 2015;58(5):862870.

8. Guilhem I, Balkau B, Lecordier F, et al.: Insulin pump failures are still frequent: a prospective study over 6 years from 2001 to 2007. Diabetologia. 2009;52(12):2662-2664.

9. Wheeler BJ, Heels K, Donaghue KC, et al.: Insulin pump-associated adverse events in children and adolescents--a prospective study. Diabetes Technol Ther. 2014;16(9):558562.

10. Scaramuzza $A E$, Dell'Acqua $M$, Macedoni $M$, et al.: Insulin pump therapy in children with type 1 diabetes: the dark side of the moon. J Diabetes Sci Technol. 2013;7(4):10951097.

11. Pickup JC, Yemane N, Brackenridge A, et al.: Nonmetabolic complications of continuous subcutaneous insulin infusion: a patient survey. Diabetes Technol Ther. 2014;16(3):145149.

12. Ross PL, Milburn J, Reith DM, et al.: Clinical review: insulin pump-associated adverse events in adults and children. Acta Diabetol. 2015;52(6):1017-1024. 
Fig. 1a - Overall survival time, with a median of 26 months

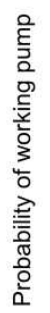

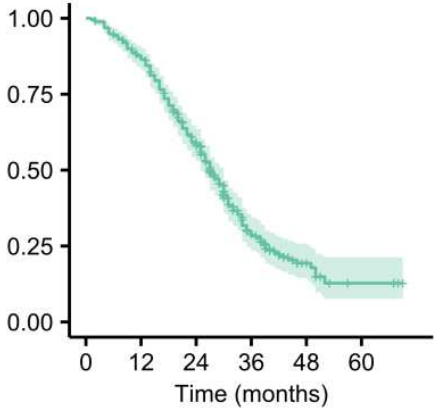

Number at risk by time

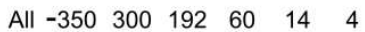

$$
\begin{aligned}
& \begin{array}{llllll}
1 & 12 & 24 & 36 & 48 & 60
\end{array} \\
& \text { Time (months) }
\end{aligned}
$$

Fig. $1 \mathrm{~b}$ - Survival according to failure type
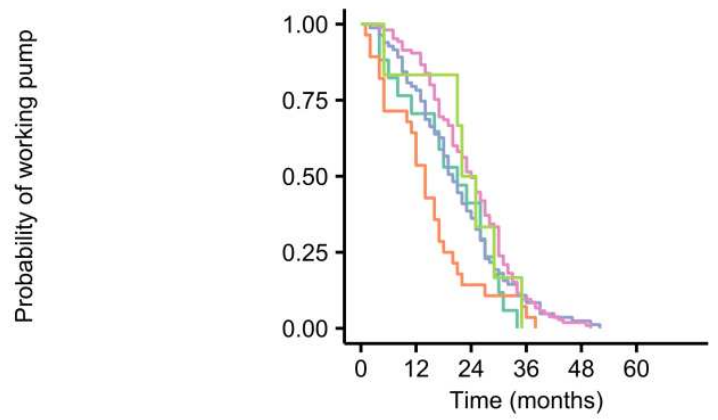

Number at risk by time

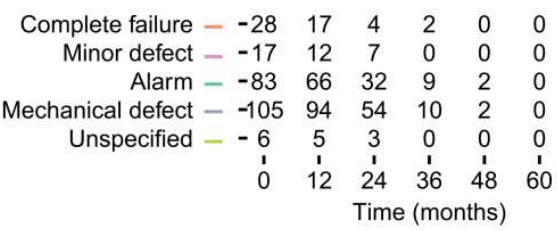

Fig. 1c - Survival according to pump models

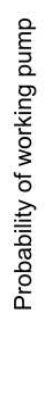

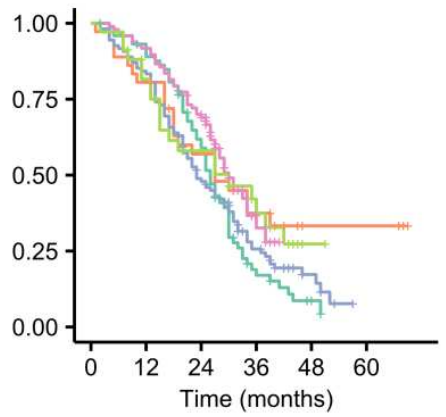

Number at risk by time

$$
\begin{aligned}
& \text { MedtronicParadigm512 + }-\begin{array}{lllllll}
-36 & 29 & 18 & 10 & 4 & 4
\end{array} \\
& \text { MedtronicParadigm522 + } \begin{array}{lllllll}
-108 & 91 & 51 & 22 & 6 & 0
\end{array} \\
& \text { Medtronic Veo + }-97 \begin{array}{llllll}
99 & 66 & 10 & 0 & 0
\end{array} \\
& \text { AccuChekCombo + } \begin{array}{llllll}
-35 & 25 & 16 & 9 & 1 & 0
\end{array} \\
& \text { Animas } 20 / 20+\begin{array}{cccccc}
-74 & 66 & 42 & 10 & 3 & 0
\end{array}
\end{aligned}
$$

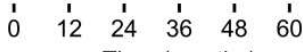

$$
\begin{aligned}
& \text { Time (months) }
\end{aligned}
$$

Fig. 1d - Survival according to age at pump initiation
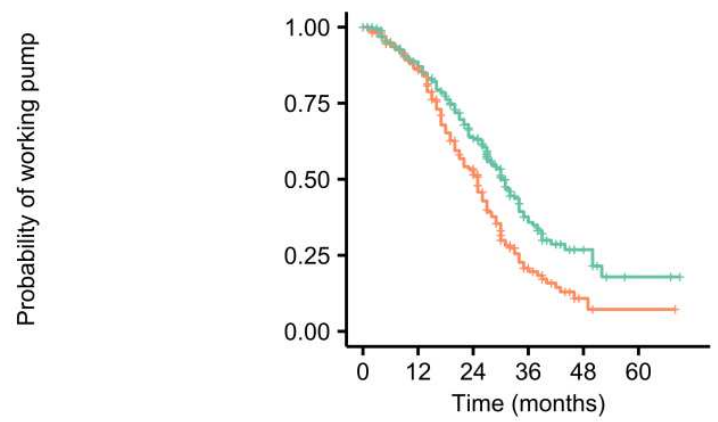

Number at risk by time

$$
\begin{array}{rrrrrrrr}
\text { Younger than } 40 \text { years }+-161 & 137 & 79 & 19 & 3 & 1 \\
\text { Older than } 41 \text { years }+\begin{array}{rrrrrrr}
-189 & 163 & 114 & 42 & 11 & 3 \\
& 0 & 12 & 24 & 36 & 48 & 60
\end{array}
\end{array}
$$




\begin{tabular}{|c|c|c|c|c|c|c|c|c|c|c|c|c|c|c|}
\hline \multirow{3}{*}{$\begin{array}{l}\text { Pump brand } \\
\text { Pump model } \\
\text { Number of defects } \\
\text { and time before } \\
\text { defect }\end{array}$} & \multirow{2}{*}{\multicolumn{2}{|c|}{ Total of pumps }} & \multicolumn{6}{|c|}{ Medtronic } & \multirow{2}{*}{\multicolumn{2}{|c|}{$\begin{array}{c}\text { Roche } \\
\text { Accucheck }^{\circledR} \text { Combo }\end{array}$}} & \multicolumn{2}{|c|}{ Animas } & \multirow{2}{*}{\multicolumn{2}{|c|}{$p$ value }} \\
\hline & & & \multicolumn{2}{|c|}{ Paradigm $^{\circledR} 512 / 712$} & \multicolumn{2}{|c|}{ Paradigm $^{\circledR} 522 / 722$} & \multicolumn{2}{|c|}{ Paradigm ${ }^{\circledR} \mathrm{Veo}^{\mathrm{TM}}$} & & & \multicolumn{2}{|c|}{$20 / 20$} & & \\
\hline & n (\%) & $\begin{array}{l}\mathbf{t} \quad[\mathrm{IQR}] \\
\text { (months) }\end{array}$ & n (\%) & $\begin{array}{l}\mathbf{t} \quad[\mathrm{IQR}] \\
\text { (months) }\end{array}$ & n (\%) & $\begin{array}{l}\mathbf{t} \quad[\mathrm{IQR}] \\
\text { (months) }\end{array}$ & n (\%) & $\begin{array}{l}\mathbf{t} \quad[\mathrm{IQR}] \\
\text { (months) }\end{array}$ & n (\%) & $\begin{array}{l}\mathbf{t}[\mathrm{IQR}] \\
\text { (months) }\end{array}$ & n (\%) & $\begin{array}{l}\mathbf{t} \quad[\mathrm{IQR}] \\
\text { (months) }\end{array}$ & $\mathbf{n}$ & $\mathbf{t}$ \\
\hline Complete failure & $28 \quad(12)$ & 13 [5-17] & $4 \quad(18)$ & 10 [4-17] & 8 (9) & 10 [3-13] & $6 \quad(12)$ & $16[11-20]$ & $3(15)$ & 34 [30-34] & $7 \quad(12)$ & 12 [7-15] & 0.72 & 0.89 \\
\hline Alarm & $17(7)$ & 20 [11-27] & $2(9)$ & 11 [7-14] & 3 (4) & 8 [6-14] & $11(21)$ & $26[19-28]$ & $1(5)$ & 11 [11-11] & $0 \quad(0)$ & $0 \quad[0]$ & $<0.001$ & 0.016 \\
\hline $\begin{array}{l}\text { Total of severe } \\
\text { failures }\end{array}$ & $45 \quad$ (19) & $15 \quad[8-23]$ & $6 \quad(27)$ & $10 \quad[4-17]$ & 11 (13) & 10 [3-13] & 17 & 23 [16-28] & $4 \quad(20)$ & $30 \quad[23-34]$ & $7 \quad$ (12) & $12 \quad[7-15]$ & 0.02 & 0.62 \\
\hline Mechanical defect & $83 \quad(35)$ & 19 [13-26] & $14(64)$ & 18 [11-26] & $29 \quad(34)$ & 18 [10-28] & $27 \quad(53)$ & 21 [14-25] & $3 \quad(15)$ & 27 [14-34] & 10 (17) & 24 [18-27] & $<0.001$ & 0.06 \\
\hline Minor defect & 105 (44) & 24 [16-30] & $2(9)$ & 23 [19-28] & $44 \quad(51)$ & $23[16-30]$ & $6 \quad(12)$ & 24 [14-27] & $13(65)$ & 14 [11-16] & $40 \quad(66)$ & 25 [21-30] & $<0.001$ & $<0.001$ \\
\hline $\begin{array}{l}\text { Total of not severe } \\
\text { failures }\end{array}$ & 188 (79) & 21 [15-29] & $16 \quad$ (73) & 18 [13-27] & $73 \quad$ (85) & 21 [14-30] & $33 \quad(65)$ & $21 \quad[14-26]$ & $16 \quad(80)$ & $14 \quad[10-21]$ & $50 \quad(83)$ & $25 \quad[20-30]$ & 0.02 & 0.003 \\
\hline Unspecified & $6 \quad(2)$ & 23 [21-27] & $0 \quad(0)$ & $0 \quad[0]$ & $2(2)$ & 30 [27-32] & $1(2)$ & 28 [28-28] & $0 \quad(0)$ & $0 \quad[0]$ & 3 (5) & 21 [12-21] & 0.78 & 0.36 \\
\hline Total of defects & 239 (68) & 21 [14-28] & 22 (61) & $17 \quad[9-26]$ & $86 \quad(80)$ & 19 [13-30] & 51 (53) & 21 [14-27] & 20 (57) & 15 [11-27] & 60 (81) & 24 [18-29] & $<0.001$ & 0.048 \\
\hline
\end{tabular}

Table 1: Number of pump defects $(\mathrm{n})$ and time before defect $(\mathrm{t})$ according to pump model and type of defect. P-values were calculated for each type of defect comparing pump models. Complete failures and alarms were considered as "severe failures". Mechanical defects and minor defects were considered as "not severe failures" 
Table 2. Univariate and multivariate Cox proportional analysis for failure-free survival $(n=390)$

\begin{tabular}{|c|c|c|c|c|}
\hline & \multicolumn{2}{|c|}{ Univariate analysis } & \multicolumn{2}{|c|}{ Multivariate analysis } \\
\hline & $\mathrm{HR}(95 \% \mathrm{Cl})$ & $P$ value & $\mathrm{HR}(95 \% \mathrm{Cl})$ & $P$ value \\
\hline \multicolumn{5}{|l|}{ Brand (ref: Medtronic) } \\
\hline Roche & $0,93(0,58 ; 1,42)$ & 0,76 & - & - \\
\hline Animas & $1,29(0,96 ; 1,74)$ & 0,093 & - & - \\
\hline \multicolumn{5}{|l|}{ Model (ref: Medtronic Paradigm 512/712) } \\
\hline Paradigm 522/722 & $1,49(0,93 ; 2,38)$ & 0,097 & $1,21(0,72 ; 2,01)$ & 0,47 \\
\hline Medtronic Veo & $1,00(0,60 ; 1,66)$ & 0,99 & $0,78(0,44 ; 1,36)$ & 0,38 \\
\hline Roche Combo & $1,13(0,62 ; 2,08)$ & 0,68 & $0,77(0,39 ; 1,48)$ & 0,43 \\
\hline Animas 20/20 & $1,57(0,96 ; 2,57)$ & 0,07 & $1,18(0,69 ; 2,02)$ & 0,54 \\
\hline CSII treatment duration (months) & $0,98(0,97 ; 1,007)$ & 0,24 & $1,00(0,99 ; 1,00)$ & 0,97 \\
\hline \multicolumn{5}{|l|}{ Gender (ref: male) } \\
\hline $\begin{array}{l}\text { Female } \\
\text { Age at diabetes diagnosis (ref: } 0 \text { to } 15 \text { years) }\end{array}$ & $1,40(1,06 ; 1,86)$ & 0,018 & $1,22(0,89 ; 1,66)$ & 0,20 \\
\hline 16 to 30 years & $0,76(0,57 ; 1,02)$ & 0,07 & & - \\
\hline 31 to 45 years & $0,62(0,41 ; 0,93)$ & 0,02 & & - \\
\hline More than 46 years & $0,55(0,29 ; 1,04)$ & 0,06 & & - \\
\hline \multicolumn{5}{|l|}{ Diabetes type (ref: type 2 or other) } \\
\hline Type 1 & $0,92(0,55 ; 1,56)$ & 0,77 & $0,97(0,50 ; 1,89)$ & 0,94 \\
\hline $\begin{array}{l}\text { Age at first pump (ref : more than } 40 \text { years) } \\
0 \text { to } 40 \text { years }\end{array}$ & $1,59(1,23 ; 2,05)$ & 0,0003 & $1,64(1,19 ; 2,25)$ & 0,002 \\
\hline \multicolumn{5}{|l|}{ Number of previous pump (ref: none) } \\
\hline 1 & $0,85(0,64 ; 1,14)$ & 0,28 & $0,98(0,72 ; 1,32)$ & 0,89 \\
\hline 2 & $0,94(0,60 ; 1,46)$ & 0,78 & $1,00(0,61 ; 1,64)$ & 0,99 \\
\hline 3 or more & $0,97(0,43 ; 2,2)$ & 0,94 & $1,09(0,47 ; 2,55)$ & 0,84 \\
\hline \multicolumn{5}{|l|}{ Number of previous failure (ref: none) } \\
\hline 1 & $1,04(0,76 ; 1,43)$ & 0,80 & - & - \\
\hline 2 or more & $1,26(0,74 ; 2,13)$ & 0,39 & - & - \\
\hline
\end{tabular}

Multivariate analysis was stratified according to centers where CSII was initiated.

Selection of variables for multivariate analysis was done a priori without any specific automatic selection procedure. Brand, Age at diabetes diagnosis and number of previous failure were not included in the multivariate analysis due to collinearities with respectively Models, Age at first pump and number of previous pump. 